NBER WORKING PAPER SERIES

\title{
USING NON-PECUNIARY STRATEGIES TO INFLUENCE BEHAVIOR: EVIDENCE FROM A LARGE SCALE FIELD EXPERIMENT
}

\author{
Paul J. Ferraro \\ Michael K. Price \\ Working Paper 17189 \\ http://www.nber.org/papers/w17189
NATIONAL BUREAU OF ECONOMIC RESEARCH
1050 Massachusetts Avenue
Cambridge, MA 02138
July 2011

The authors thank Kathy Nguyen for her support in conducting this experiment and for her assistance in creating the treatment messages and ensuring the experimental design was policy relevant. The authors also thank Herb Richardson for transferring the outcome data, Merlin Hanauer and Juan Jose Miranda for work to compile the data. John List, Subrendu Pattanayak, Laura Taylor, and participants at the 2009 AEA-ASSA meetings and seminars at the Georgia Water Wise Council, the Georgia Association of Water Professionals, University of California-Davis, North Carolina State University, Virginia Tech, and Yale University provided useful comments that markedly improved the study The views expressed herein are those of the authors and do not necessarily reflect the views of the National Bureau of Economic Research.

NBER working papers are circulated for discussion and comment purposes. They have not been peerreviewed or been subject to the review by the NBER Board of Directors that accompanies official NBER publications.

(C) 2011 by Paul J. Ferraro and Michael K. Price. All rights reserved. Short sections of text, not to exceed two paragraphs, may be quoted without explicit permission provided that full credit, including $@$ notice, is given to the source. 
Using Non-Pecuniary Strategies to Influence Behavior: Evidence from a Large Scale Field Experiment

Paul J. Ferraro and Michael K. Price

NBER Working Paper No. 17189

July 2011

JEL No. C93,D03,Q2

\begin{abstract}
Policymakers are increasingly using norm-based messages to influence individual decision-making. We partner with a metropolitan water utility to implement a natural field experiment examining the effect of such messages on residential water demand. The data, drawn from more than 100,000 households, indicate that social comparison messages had a greater influence on behavior than simple pro-social messages or technical information alone. Moreover, our data suggest social comparison messages are most effective among households identified as the least price sensitive: high-users. Yet the effectiveness of such messages wanes over time. Our results thus highlight important complementarities between pecuniary and non-pecuniary strategies.
\end{abstract}

Paul J. Ferraro

Georgia State University

prcpjf@langate.gsu.edu

Michael K. Price

Department of Economics

University of Tennessee

515 Stokely Management Center

Knoxville, TN 27996

and NBER

mprice21@utk.edu 


\section{Introduction}

Most travelers have been confronted with a strategically placed card in a hotel washroom urging them to protect the environment by reusing their towels. Such efforts are consistent with a growing trend of employing non-pecuniary strategies (e.g., norm-based messages and social comparisons) to influence individual decision-making. As noted by Schultz et al. (2007), such strategies have been applied to a range of behaviors including alcohol and drug use, eating disorders, gambling, recycling, and energy consumption. Although the use of such strategies continues to grow in popularity, their relative efficacy remains under-researched amongst economists.

In an attempt to fill this gap, we examine the effectiveness of non-pecuniary strategies as a means to manage residential water demand. To maintain consistency with existing policy initiatives, we focus our analysis on three commonly employed conservation strategies: (i) the dissemination of information on behavioral and technological modifications, (ii) appeals to prosocial preferences, and (iii) the provision of social comparisons to enhance appeals to pro-social preferences. To the best of our knowledge, we provide the first apples-to-apples comparison of programs based on appeals to pro-social preferences with those augmented with social comparisons.

We focus our analysis on residential water demand for two reasons. First and foremost, policymakers frequently rely upon non-pecuniary measures rather than market-based approaches to promote conservation efforts and manage water resources. For example, such strategies are the essence of the EPA's Water Sense program - a public education campaign launched in 2006 to spread word about the importance of water efficiency and conservation. 
Second, during the $20^{\text {th }}$ Century, global water use increased six-fold - a pattern that has prompted many to identify the availability of fresh water as one of the most critical issues confronting policymakers in the twenty-first century. The United Nation's Environmental Program estimates that by 2025 over two-thirds of the world's population will reside in regions considered water stressed. Similar concerns abound in the United States where a recent government survey suggests that at least 36 states are anticipating some form of water shortage by 2013 . Thus water scarcity concerns are likely to magnify over time.

We begin by developing a conceptual framework based on the work of Levitt and List (2007) to identify channels through which norm-based strategies may influence household water consumption. The framework affords a rank ordering over the expected influence of commonly enacted conservation strategies on consumption decisions. Empirically, we investigate the relative effectiveness of such strategies by partnering with a metropolitan water utility to implement a large-scale, natural field experiment. Our field experiment includes data on more than 100,000 residential households randomized into four treatments: a control group, a group that received technical advice, a group that received both technical advice and an appeal to prosocial preferences, and a group that received technical advice and an appeal to pro-social preferences augmented with a social comparison.

Our study builds upon two distinct literatures. The first is a growing body of work that examines the use of pro-social messages and/or social comparisons in the context of charitable giving (see, e.g., Bryan and Test, 1967; Reingen, 1978; Frey and Meier, 2004; Croson and Shang, 2007; Martin and Randal, 2008; Shang and Croson, 2008). Despite the seemingly amorphous nature of public goods and common pool resource games, it is not clear that results from the former would necessarily generalize to the latter. As noted in Sandler and Arce (2003), 
“....Individuals appear to place a premium on inaction which requires sacrificing a right, so that the commons problem may pose a greater policy dilemma...." Moreover, many of these studies (e.g., Frey and Meier, 2004; Croson and Shang, 2007; Shang and Croson 2008) focus on the decisions of individuals along the intensive margin - i.e., previous donors or those actively planning to donate at the time of intervention. ${ }^{1}$ Hence, this literature provides little insight regarding the effectiveness of such strategies on behavior along the extensive margin.

The second is a growing body of work in social psychology that examines the use of social-norm marketing, feedback, and tailored information campaigns to promote environmental conservation (see, e.g., Hutton and McNeill, 1981; Luyben, 1982; Siero et al., 1996; Kurz et al., 2005; Schultz et al., 2007; Goldstein et al., 2008; Nolan et al., 2008). However, almost all of these studies rely upon s mall samples that were often informed about the study prior to any intervention (e.g., Luyben, 1982; Kurz et al., 2005; Schultz et al., 2007; Nolan et al., 2008). ${ }^{2}$ Further, many of these studies rely upon s elf-reported measures of behavioral change (e.g., Hutton and McNeill, 1982; Luyben, 1982; Nolan et al., 2008) which may introduce a powerful confound when attempting to generalize results to other settings (social desirability bias).

Several insights emerge from our field study. First, non-pecuniary motivations influence water consumption in ways consonant with our conceptual framework. For example, technical advice has a small impact on water use - households in this treatment consume approximately 1 percent less than counterparts in the control. Augmenting technical advice with an appeal to prosocial preferences and as ocial comparison generates a substantially larger reduction approximately 4.8 percent. From a policy perspective, these differences suggest that

\footnotetext{
${ }^{1}$ Frey and Meier (2004) examine the effect of social comparisons amongst all students, but only find a significant effect when the sample is restricted to students who contributed to the charity in the past.

${ }^{2}$ For example, Kurz et al. (2005) use a final sample of 166 households allocated into one of eight treatment conditions. Participants were recruited by way of an initial information letter detailing the nature of the study with response rate for the different treatments ranging from 29.1 to 48.9 percent.
} 
there are high returns to explaining why customers should reduce water consumption rather than outlining how best to reduce water use.

Interestingly, this estimated social comparison effect is equivalent to that which would be expected if average prices were to increase approximately 12 to 15 percent. ${ }^{3}$ Under the current pricing system, such a price increase would translate into an approximate $\$ 5$ per month increase in water bills for the median user in our sample. Moreover, the estimated treatment effect is more than twice that observed across recent programs using social comparisons to affect energy conservation (see Allcott 2009; Ayres et al. 2009).

Second, we find a fundamental difference in the efficacy of norm-based messages across low and high-use households. For example, there is an approximate 94.1 percent difference in the relative treatment effect across user groups in our strong social norm treatment. From a policy perspective, heterogeneity in the effectiveness of norm-based appeals is notable as highuse households tend to be less price sensitive than others (Mansur and Olmstead, 2007). Thus non-pecuniary strategies provide a useful complement to pecuniary measures because they are most effective amongst the group that is least sensitive to price changes.

Finally, the effectiveness of non-pecuniary strategies wanes over time. In the month following intervention, households in our strong social norm treatment use approximately 5.62 percent less water than counterparts in our control group. F our months later, the estimated difference across these groups declines by 35.4 percent. This observed waning is consonant with previous work suggesting the impermanence of non-pecuniary incentives (see, e.g., Gneezy and List, 2006; Curtis and Price, 2009; Landry et al., 2009). Interestingly, our data suggest that waning is driven almost entirely by the high user group.

\footnotetext{
${ }^{3}$ This comparison is based upon recent estimates of price elasticity of demand for U.S. metropolitan residential customers, which fall in the range of -0.33 to -0.36 (Mansur and Olmstead, 2007; Olmstead et al., 2007).
} 


\section{Conceptual Framework}

We develop a conceptual framework in the spirit of Levitt and List (2007) to identify possible channels through which policy measures such as information transfers and pro-social messages may influence household water consumption. O ur framework posits an agent with utility that is additively separable over two terms - consumption utility, c, and a moral payoff, M. Both of these terms depend on a single action, $a$, the choice of water consumption and a vector of individual specific characteristics, $\theta$. A s in Levitt and List (2007), M captures nonpecuniary impacts associated with the choice of action and depends upon the extent to which the decision-maker's actions are scrutinized, $s$, and the perceived saliency (strength) of the set of social norms, $n$, that dictate acceptable levels of water consumption.

The utility function for agent $i$ is specified as:

$$
U_{i}(a, n, s ; \theta)=c_{i}(a ; \theta)-M_{i}(a, n, s ; \theta)
$$

where consumption utility, $\mathrm{c}($ ), is strictly increasing and concave in $a$. Given the common nature of water supplies, consumption imposes negative externalities on ot hers through the depletion of resource stocks. Hence, $\mathrm{M}(\cdot)$ is assumed increasing and convex in $a$. As in Levitt and List (2007), we assume that moral costs are strictly increasing in the extent to which actions are scrutinized (observed) by others and the extent to which actions deviate from the perceived social norm.

Our conceptual framework highlights how policymakers could influence water use by employing non-pecuniary strategies that target and affect the realization of $s$ and $n$. For example, consider a program, such as EPA's Water Sense, that frames conservation as a social norm. Under our framework, this frame should map into an increased realization of $n$ and an associated increase in the disutility (moral cost) of any prior consumption level. As consumption utility is 
assumed increasing and strictly concave in $a$, we would therefore expect a reduction in overall water use to offset this increased "marginal cost".

We implement a series of experimental treatments designed to systematically augment the realization of these factors, allowing us to rank the expected ordering of each treatment. Our treatments are based upon existing conservation programs and focus on three commonly employed strategies: (i) the dissemination of information on behavioral and technological modifications, (ii) requests to voluntarily restrict use and preserve scarce resources, and (iii) the provision of social comparisons to induce conformity and make salient the norm of conservation. ${ }^{4}$ Moreover, to maintain consistency with existing policy initiatives, we consider interventions that combine technical and behavioral information and norm-based appeals.

Our first treatment, a technical advice letter, works though a single channel - increased scrutiny - and therefore is predicted to have the smallest effect on overall patterns of consumption. Our second treatment augments the technical advice letter by including an appeal to pro-social preferences highlighting the importance of conserving water. To the extent that such appeals highlight a social norm - conservation and concern for the environment - we would thus expect to see additional reductions in average use. Our final treatment makes the social norm more salient by including a social comparison that contrasts the household's use in the previous year with median use in the county. We would thus expect this treatment to generate the largest reductions in overall water consumption - particularly amongst high-use households.

Conceptually, the inclusion of the weak social norm treatment affords a be tter understanding of the channels through which appeals to pro-social preferences and social comparisons influence behavior. Importantly, this treatment allows us to differentiate our model

\footnotetext{
${ }^{4}$ Our final two treatments are similar in spirit to Goldstein et al. (2008) who compare the relative effectiveness of appeals for hotel guests to reuse towels as a means to "help save the environment" with appeals that augmented this message to include a descriptive norm informing guests about participation in the program by prior visitors.
} 
from alternatives that focus on imperfect information in the spirit of Becker's (1965) household production framework. The weak social norm treatment reveals no i nformation about the behavior of others that a household could use to update beliefs and re-evaluate consumption decisions. Consequently, models based solely on imperfect information would predict similar patterns of consumption across our technical advice and weak social norm treatments. In contrast, our framework predicts very different patterns of use across these treatments.

\section{Experimental Environment and Design}

Cobb County is part of the metropolitan statistical area of Atlanta, Georgia. In 2006, it contained an estimated 679,325 people $-71 \%$ of whom self-identified as White/Caucasian and $23 \%$ as Black. ${ }^{5}$ The county is not known for environmentalism. The current Congressmen have some of the lowest League of Conversation Voter scores (LCV, 2008) recorded in 2007 and 2008. During this same time period, Georgia's Senate delegation tied for last place in the League's scorecard. Hence, we have not selected a subject pool particularly known for proenvironmental preferences. As noted in Costa and Kahn (2010), the conservative nature of our subject pool may serve to mitigate observed treatment effects from social comparisons.

The Cobb County Water System (CCWS), an agency of the Cobb County Government, distributes treated surface water for about 170,000 Cobb County customers. Of these, about 150,000 are residential customers that reside in single-family dwellings. ${ }^{6}$ CCWS obtains its water from disputed surface supplies that have been affected by periodic drought conditions that began in 1998. Starting in 2006, the CCWS created a number of initiatives to encourage water conservation among its customers. On January 1, 2006, it introduced a new tiered-rate pricing

\footnotetext{
${ }^{5}$ Additional information about Cobb County can be viewed at http://quickfacts.census.gov/qfd/states/13/13067.html ${ }^{6}$ In 2000, Cobb County was Georgia's second largest user of the public water supply accounting for almost $8 \%$ of statewide consumption (Fanning, 2003). Within the county, residential water use is highly variable with about 5\% of the customers using about $18 \%$ of the water (unpublished data, CCWS).
} 
scheme to replace the previously fixed-price-per-gallon pricing scheme. Concurrently, CCWS also initiated a number of supplemental programs designed to inform consumers how and why to conserve water. These initiatives, however, were not targeted towards individual households and remained available to all households throughout the post-intervention period of analysis. As such, our experiment likely provides a conservative test of the ability of policy-makers to harness pro-social preferences to achieve policy goals.

\section{Experimental Design}

To reduce water use among its residential customers in the summer of 2007, the CCWS agreed to initiate a targeted, mail-based residential customer conservation education program through a randomized experimental design. ${ }^{7}$ The aim of the program was to provide CCWS empirical evidence on the relative effectiveness of providing residential customers (i) a message about ways in which they could reduce their water use most effectively, i.e., the "how" of reducing water use, and (ii) a message that appealed to pro-social preferences, i.e., the "why" of reducing water use. Each treatment was designed in collaboration with CCWS employees and pre-tested using small focus groups of residential customers from neighboring counties.

\section{Treatment 1 - Technical Advice}

Our first treatment provided households an "information-only" message that included a two-sided "tip sheet" listing ways to most effectively reduce water use and whom to contact for more information (see Appendix 1). All letters were personalized and sent to households in official CCWS envelopes as first class mail, and thus we expect that households perceived increased scrutiny over consumption decisions. Because moral costs are increasing in scrutiny, we would expect an increase in the disutility (moral cost) associated with any prior level of

\footnotetext{
${ }^{7}$ In the taxonomy of Harrison and List (2004) our approach would be considered an example of a natural field experiment.
} 
consumption. As consumption utility is strictly concave in $a$, the household must lower overall consumption to offset this increased marginal cost. We would thus expect to observe a reduction in average water use relative to households in our control group.

Undoubtedly, there are other channels through which this treatment could operate if households were unaware of the strategies highlighted on the tip sheet. However, as the information contained in the "tip sheet" was widely available prior to our intervention, it is unlikely that such effects would be very pronounced. Yet, we cannot rule out this possibility. It would thus be remiss if we did not note that increased scrutiny is not the only reason one might observe reduced water use in this treatment.

\section{Treatment 2 - Weak Social Norm}

Our second experimental treatment augments Treatment 1 by including a personally addressed letter on official CCWS stationary that was signed by the Water Conservation Coordinator. The letter includes standard, norm-based language from water conservation materials used both nationally, and in Georgia, as well as information found on the customer's month bill (and tip sheet) including whom to contact for more information about water conservation. The letter in part reads:

As you know, Cobb County's water resources are stretched because of population growth and many years of low rainfall. Cobb County residents consume almost one of out every ten gallons of Georgia's public water supply. As a result, our water use has a large impact on the ability of Georgia's waterways to protect wildlife and dilute pollutants that threaten human health. We all need to work together to use water wisely....

We need your help. Act on the tips listed in the enclosed tip sheet. We all have to do our part to protect Cobb County's precious water resources. Reducing our water consumption today is important for preserving our environment and our economy for future generations. Please don't waste water. Remember: every drop counts! 
In addition to the effects on scrutiny, the inclusion of pro-social appeals may enhance the disutility associated with any level of consumption through an increased realization of $n$ - the set of social norms affecting water use. We would thus expect larger reductions in average water use than those observed in Treatment 1.

Treatment 3 - Strong Social Norm

Social psychologists often stress that attention can be drawn to social norms most saliently through social comparisons. Our final treatment takes the pro-social appeals from our weak social norm treatment and adds a comparison of the household's water use from June to October 2006 to the median County household use for the same period, and the percentile in which the household fell during this period. ${ }^{8}$ This comparison reads:

As we enter the summer months, we thought that you might be interested in the following information about your water consumption last year:

\section{Your own total consumption June to October 2006: $\quad 52,000$ gallons}

Your neighbors' average (median) consumption June to October 2006: 35,000 gallons

You consumed more water than $73 \%$ of your Cobb County neighbors.

Based on focus groups and prior work from social psychology (see, e.g., Cialdini et al., 2006; Schultz et al., 2007), the percentile text was framed was in a negative way to emphasize how many people do not engage in the targeted behavior. See Appendix 1 for an example of the full letter.

This final treatment message is expected to influence behavior through two distinct channels. First, the inclusion of a social comparison may further strengthen the perceived social

\footnotetext{
${ }^{8}$ Technically, the data presented to the household are for billed use dated June to October 2006 (May through September use). Focus groups indicated that recipients may wish to verify the information in the letter and would look to their recent bill as the relevant source. Monthly bills show very prominently, near the top of the first page, a histogram documenting the billed month's use and each of the previous twelve billed months' use.
} 
norm - i.e., the realization of $n$ in our model. Second, the provision of such detailed information may also enhance the extent to which the household perceives its actions are scrutinized. Ceteris paribus, we would therefore expect a greater reduction in average water use than that observed in Treatment 2.

Before proceeding to the results section, a few key features of our experimental design should be highlighted. First, the CCWS required a minimum detectable treatment effect of a 2 percent decline in average water use and statistical power of at least 0.90 - a request that required a sample size of 11,600 for each treatment message group and a control group of at least 69,600 households. ${ }^{9}$ Second, the three treatment mailings were sent out on the same day during the week of 21 May 2007. All mailings were sent via first-class mail in official CCWS envelopes to maximize the likelihood that they would be opened by customers and to clearly associate the messages with CCWS. A follow-up tip sheet was sent four weeks later in the same manner to all treated customers. For Treatments 2 and 3, copies of the original personalized letters did not accompany this mailing because the CCWS indicated that they would not have sent follow-up letters in a non-experimental version of their education program. ${ }^{10}$

Third, meters are read and bills are sent out daily based on a household's assignment to one of 390 "meter routes." To ensure that we have no systematic differences across treatments in the day of the month an outcome is measured, we randomize treatment assignment within meter routes which correspond to neighborhood sections. Such stratification has the additional benefit

\footnotetext{
${ }^{9}$ These sample sizes were derived using the desired minimum treatment effect, water use data from summer 2006 , an assumed 0.70 intra-household annual correlation of water use (based on CCWS data), and a Type I error rate of 0.05 .

${ }^{10}$ Our single treatment "dose" contrasts with previous work (Allcott, 2009; Ayres et al., 2009) in which conservation materials are sent monthly/quarterly without cessation.
} 
of increasing the precision of the estimates provided that unobservables affecting treatment response are more similar within rather than between meter routes. ${ }^{11}$

Fourth, the strong social norm message requires the communication of baseline water use for summer 2006. Although the water system billed 156,326 residential customers in April 2007, this requirement limits the set of households eligible for treatment assignment to 139,693 households whose customer billing names had not changed between May 2006 and March 2007. Fifth, under a nonrandomized conservation message program, CCWS would not send messages to individuals who consume fewer than 4,000 gallons/month or who use zero gallons for most of the summer water season. Households that met these criteria for May through September 2006 were excluded from our final sample. Using these procedures, 11,699 households (HHs) were assigned to Treatment 1, 11,695 HHs were assigned to Treatment 2, 11,699 HHs were assigned to Treatment 3, and 71,779 HHs were assigned to the control condition. ${ }^{12}$ Finally, monthly preand post-experiment water use data come from the CCWS billing department.

\section{Experimental Results}

We begin by examining the effect of our experimental treatments on household water use for June through September 2007. The first column of Table 1 summarizes water use for this period and the second column the percentage change in average use relative to that observed during this same time period in 2006. The data in Table 1 exclude 187 households whose water was turned off during the months June through September 2007, thirteen households for whom we cannot determine with certainty actual water use due to billing mistakes, and three households with large catastrophic leaks of at least one million gallons.

\footnotetext{
${ }^{11}$ For over $90 \%$ of the routes in our sample, the coefficient of variation in 2006 summer water use is lower within routes than across routes.

${ }^{12}$ Using STATA 10 "sample" command and "by" option.
} 
As noted in the second column of Table 1, average water use in summer 2007 declined relative to that observed for summer 2006 a cross all household types. However, the observed decline across our three treatment groups is approximately 7.41 to 53.38 percent greater than that observed amongst our control group. Moreover, the observed rank ordering of treatment effects corresponds to that predicted by our conceptual framework. We observe the smallest decline in Treatment 1 and the largest decline in Treatment 3. Importantly, the estimated differences in treatment effects are statistically significant at the $\mathrm{p}<0.05$ level using parametric and nonparametric tests. $^{13}$

Taken jointly, these differences suggest a first result:

Result 1: Non-pecuniary motivations influence average water use. As we increase the scrutiny of actions and the perceived saliency of social norms, we observe greater reductions in average consumption.

Result 1 is consistent with the hypothesis that moral payoffs influence consumption decisions for the average household in our sample. Consonant with the rank ordering predicted by our conceptual framework, we observe the smallest effect in our technical advice treatment, which works through a single channel - scrutiny. We observe the largest effect in our strong social norm treatment, which operates through multiple channels. Result 1 also accords well with Goldstein et al. (2008), who observe that significant increases in the reuse rate of hotel towels could be achieved by augmenting normative appeals to reuse with social comparisons that report the percentage of prior guests who engaged in such behavior.

\footnotetext{
${ }^{13}$ A one way ANOVA with Sidak adjustment for multiple hypotheses indicates that each treatment effect is significantly different from zero and that the effect of Treatment 3 is larger than that observed in the other treatments. Similarly, a non-parametric Jonckheree-Terpstra test for trend in summer 2007 water use indicates a significant trend as one moves from Treatment 1 to Treatment 2 to Treatment 3.
} 
Importantly, we observe a significant reduction in consumption when augmenting the technical advice letter to include an appeal to pro-social preferences. Treatment 2's impact calls into question alternate explanations for the observed data patterns that focus on i mperfect information in the context of Becker's (1965) household production model. ${ }^{14}$ Our weak social norm treatment reveals no i nformation about the behaviors of others that could lead the household to update beliefs and re-evaluate its own consumption decisions.

To increase the precision of the estimated treatment effects, we regress summer 2007 water use for the $i$ th household $\left(Y_{i 2007}\right)$ on three dummy variables representing the three treatments $\left(T_{1}=\right.$ Technical Advice; $T_{2}=$ Weak Social Norms; $T_{3}=$ Strong Social Norms):

$$
Y_{i 2007}=\alpha+\beta_{1} * \mathrm{~T}_{1}+\beta_{2} * \mathrm{~T}_{2}+\beta_{3} * \mathrm{~T}_{3}+\beta_{4} * Y_{i 2006}+\beta_{5} * Y_{i S p r i n g}+\varepsilon
$$

We include as covariates household water use for the watering season in $2006\left(Y_{i 2006}\right)$ and spring $2007\left(Y_{i S p r i n g}\right) .{ }^{15}$ This latter variable aims to capture any home or landscaping changes since 2006 but before the experiment began. To control for heteroskedasticity, we estimate robust standard errors.

These empirical estimates (in 1000s of gallons) are contained in Model A of Table 2 and provide evidence consistent with our unconditional analysis: households in all three treatment groups consume less water than those in our control group. Figure 1 depicts the estimated effects from Table 1 as percentage changes relative to the baseline group. For example, the

\footnotetext{
${ }^{14}$ For example, one could envision a situation where a household has incorrect beliefs regarding the marginal cost of increasing efficiency. Observing that the median household in Cobb County uses significantly less water could signal to such a household that the actual marginal cost of improving efficiency is lower than their original belief and lead them to reconsider consumption patterns.

${ }^{15}$ Water use in 2006 is aggregate household consumption for the months of May through October. Spring water use captures aggregate consumption for March and April.
} 
average household in Treatment 3 (strong social norm) is predicted to consume approximately 4.8 percent (or 1,740 gallons) less water than the average control group household. To better understand the magnitude of this difference, consider that a five minute shower uses anywhere from 10 to 25 gallons of water and the average top load washing machine between $40-45$ gallons of water per load.

The final two columns of Table 2 augment this basic specification. Model B augments the model to include route specific dummy variables to capture unobserved neighborhood specific characteristics that influence water consumption. ${ }^{16}$ Model $\mathrm{C}$ trims the data to exclude observations from the extreme tails of the underlying distribution of use. Empirical results from these models are qualitatively similar to those presented in Model A - we observe the smallest (largest) reductions in consumption in our technical advice (strong social norm) treatment.

Although the estimated technical advice effect in Model C is statistically different from zero, the observed reduction in average consumption level is less than the desired minimal detectable treatment effect of two percent. From a policy perspective, this calls into question the economic significance of information-only conservation efforts.

\section{Heterogeneity in Treatment Effects - Low versus High Users}

Result 1 refers to mean treatment effects. Our experimental design, however, allows us to explore treatment effects at a deeper level by examining heterogeneous impacts across user types. A key feature of our strong social norm treatment is the inclusion of a social comparison designed to increase the saliency of social norms. As highlighted in our conceptual framework, such comparisons should have a greater effect on households whose consumption exceeded that of the median Cobb County resident. To the extent that it is easier for high-use households to

\footnotetext{
${ }^{16}$ The route dummy variables are designed to capture factors such as local variations in rainfall totals or neighborhood specific requirements/social pressures to maintain a healthy, green lawn.
} 
identify easy, low-cost means to curtail consumption and adhere to a conservation norm, our framework would predict a similar but less pronounced difference across the highest and lowest user groups in our weak social norm treatment.

To examine this conjecture, we split our data into two household types - (i) low users whose consumption in summer $2006 \mathrm{w}$ as less than the median Cobb County resident and (ii) high users whose consumption in summer $2006 \mathrm{w}$ as greater than the median Cobb County resident - and re-estimate equation (1). ${ }^{17}$ Columns A and B of Table 3 present the empirical estimates, which suggest that appeals to social norms are most effective amongst high-use households. Figure 2 shows that this conclusion holds for relative as well as absolute impacts. For example, the estimated strong social norm effect for our high user group is approximately 94.1 percent greater (5.28 versus 2.72 percent relative reduction) than that for our low user group - a difference that is significant at the $\mathrm{p}<0.05$ level.

We observe a s imilar, albeit less pronounced difference, in the estimated weak social norm effect across these household types. However, the approximate 31.5 percent difference in the estimated treatment effect across high and low user types (2.88 versus 2.19 percent relative reduction) is not significant at any meaningful level. Combined, these data suggest a second result:

Result 2: A ppeals to social norms are most effective amongst high-use households. These differences are most pronounced when the appeal includes a social comparison. Result 2 highlights an important asymmetry in the effectiveness of conservation programs based upon pro-social appeals - such strategies are most salient amongst high-use households. From a policy perspective, heterogeneity in the effectiveness of norm-based appeals is notable. Mansur

\footnotetext{
${ }^{17}$ The experiment excluded households whose summer 2006 consumption was fewer than 4,000 gallons per month (see final paragraph of Section IV), effectively removing users who fell in the lower quartile of the distribution over summer 2006 use. As such, we observe approximately twice as many high-use households in our data.
} 
and Olmstead (2007) highlight that because high-use households tend to be wealthier, such users are less price sensitive than others. Result 2 suggests that norm-based, non-pecuniary strategies may prove a useful complement to pecuniary measures because they are most effective amongst the group that is least sensitive to price changes.

\section{The Waning of Treatment Effects}

Our analysis thus far has focused on changes in relative consumption levels aggregated over all summer months. Although we find evidence of treatment effects in these aggregated data, there is a growing empirical literature suggesting the impermanence of non-pecuniary incentives such as unconditional gifts for workers (Gneezy and List, 2006; Curtis and Price, 2009) and the physical attractiveness of female solicitors in door-to-door fund-raising (Landry et al., 2009).

As noted in Gneezy and List (2006) such impermanence is consistent with non-pecuniary incentives having greatest import during initial, or "hot", phases of decision-making. Social comparisons and appeals to social norms trigger strong moral sentiments during the hot phase of decision-making - i.e., the few weeks following intervention. O ver time, however, these feelings may dissipate as the household's focus of attention shifts elsewhere. Hence, a similar pattern of decay is plausible in our setting.

By design, treatment mailings were sent to all households in our sample on the same day during the week of 21 May 2007. Our design thus allows an evaluation of whether our conservation strategies are subject to the same type of decay noted for other non-pecuniary incentives that influence decision-making through psychological processes. In this spirit, we regress separately June 2007 (September 2007) water consumption for the $\mathrm{i}^{\text {th }}$ household on June 
2006 (September 2006) consumption for that household and a vector of indicators for our different experimental treatments.

Results for these regressions are contained in the first two columns of Table 4 and provide empirical evidence of waning. For example, as noted in Column A, the estimated effect of our strong social norm letter on J une 2007 consumption was an approximate 5.62 pe rcent reduction relative to the control group. By September, the estimated difference across these two groups falls to 3.63 percent. This approximate 35.4 percent reduction in the estimated strong social norm effect across the summer months is statistically significant at the $\mathrm{p}<0.05$ level. ${ }^{18}$ We observe similar patterns of decay in both the weak social norm and technical advice treatments.

Combined these data provide evidence consonant with previous work highlighting the impermanence of non-pecuniary incentives and suggest a third result:

Result 3: Treatment effects are most pronounced in the month following intervention and decay over the course of the summer.

For behavioral economists, Result 3 adds to a mounting body of evidence from field studies suggesting that the effectiveness of incentives designed to trigger psychological processes may differ markedly across "hot" and "cold" phases of decision-making. In this regard, our data accord well with Gneezy and List (2006) who show that the effects of gifts on worker effort and short-lived and decay over the course of the work day. For practitioners, Result 3 suggests an important caveat on the use of norm-based management strategies - they are best reserved for

\footnotetext{
${ }^{18}$ A similar pattern of decay is noted in Allcott (2009) amongst households randomly assigned to groups receiving Home Energy Reports on a quarterly basis. Interestingly, Allcott (2009) reports evidence from survey data suggesting that the observed pattern of decay reflects behavior consonant with "hot" and "cold" phases of decision making. Receiving a letter reminds/motivates households to conserve energy by turning off lights, unplugging electronics, and adjusting thermostats. Over time the household tires of the change, but upon receiving the next quarter's Report is again motivated to conserve.
} 
situations where immediate, but short-lived, conservation efforts are desired. In this regard, such strategies provide a complementary measure to pecuniary-based management strategies, which are often slow to implement and difficult to adjust.

Exploring this result a level deeper by examining the persistence of treatment effects across the highest and lowest user groups in our sample (as in Columns $\mathrm{C}-\mathrm{F}$ of Table 4) suggests an important asymmetry. The observed pattern of decay is driven almost entirely by the highest user groups - an asymmetry best illustrated in Figure 3. A mongst the low user group there is no di scernable difference in the strong social norm effect across months. However, amongst the highest user group we observe an approximate 31.7 percent reduction in the relative treatment effect (6.08 versus 4.15 percent) between June and September - a difference that is significant at the $\mathrm{p}<0.05$ level. We observe similar, albeit less pronounced, patterns in both our weak social norm and technical advice treatments.

\section{Implications for Scaling Up}

We can use the results in Table 2 (Model A) to estimate aggregate impacts and costeffectiveness in a scaled-up version of the CCWS program. Had the strong social norm message (Treatment 3) been assigned to all 106,872 targeted households, summer water use in Cobb County would have been expected to decline by approximately 186 million gallons. F or perspective, such reduction is the equivalent of shutting off the water to about 5100 households. Based on the treatment costs in the experiment, CCWS would have spent $\$ 0.575$ per thousand gallons reduced. ${ }^{19}$ In contrast, if CCWS were only to target those households at or above the median historical use, it could obtain $88 \%$ of the reduction for $75 \%$ of the total cost.

\footnotetext{
${ }^{19}$ If the June tip-sheet mailing were excluded, costs would be approximately $45 \%$ lower. CCWS would also lose about $\$ 1.2$ - $\$ 1.3$ million in forgone revenues, but the education program is designed to reduce demand and thus presumably CCWS is aware of the potential for lost revenues. How much of these foregone revenues represent
} 
Given there was no statistical difference in the estimated response to the weak and strong social norm treatments for below-median water users, we also consider a hybrid policy that assigns households with above median historical use to the strong social norm treatment and all others to the weak social norm treatment. Importantly, such policy would enable CCWS to target a larger set of households that includes those for whom historical use data are missing. Under this hybrid policy, we estimate that CCWS would have affected an approximate 193 million gallon reduction in summer water use. Such reduction is equivalent to shutting off water to about 5300 hous eholds. Although the estimated cost per thousand gallons reduced for such program would be approximately 10 pe rcent higher than one focused solely on s ocial comparisons, it would eliminate an important concern of CCWS officials - complaints from below median users that could bring unwanted attention and controversy. ${ }^{20}$

\section{Conclusions}

Economists have only recently started to explore the effect of non-pecuniary strategies, such as appeals to pro-social behavior or the use of social comparisons, as a means to influence individual decision-making and promote pro-social behaviors. Much of this work has focused on the use of such strategies in the context of charitable giving. Yet such approaches have been implemented across a broader range of economically relevant settings. This study seeks to further our understanding of such strategies by exploring whether they influence household-level consumption decisions. We do so by investigating the effectiveness of policy measures based on information transfers and pro-social messages in a large-scale, natural field experiment carried out in conjunction with a water utility system in metropolitan Atlanta.

\footnotetext{
savings to consumers depends on the costs of the behavioral and technological changes made in response to treatment, which are unobservable to us.

${ }^{20}$ CCWS received some angry phone calls from such users who wanted to know why CCWS was not focusing attention and budget on above-median users.
} 
Empirical results emphasize the importance of moral payoffs on consumption decisions. As we augment the range of channels targeted by a particular conservation strategy - i.e., scrutiny or the perceived saliency of social norms - we observe greater reductions in average consumption levels. Thus policy makers are better served targeting the "why" of conservation efforts rather than the "how". Moreover, our results suggest that strategies based upon appeals to pro-social preferences and social comparisons are most effective when targeting high consumption groups. Yet the effectiveness of such policies is short-lived and wanes over time. For practitioners, this suggests an important caveat on the use of conservation strategies based upon social comparisons or appeals to social norms - they are best reserved for situations where immediate, but short-lived, conservation efforts are desired.

Undoubtedly our research has raised more questions than it has answered. For example, our analysis does not elucidate the specific channels through which our treatments affect water consumption. Future work should augment our approach and focus on variations in the social comparison message to uncover the underlying behavioral mechanisms driving our results. Understanding which theoretical models best predict behavior will help policy makers identify the most effective strategies to promote conservation efforts.

In addition, the estimated average treatment effect for our strong social norm message is more than twice that observed in similar programs targeting energy conservation (see, e.g., Allcott 2009; Ayres et al. 2009). Moreover, unlike these energy studies, we observe no evidence of a rebound effect amongst low-use households. While we would have preferred to explore these differences in greater detail, there are two important design differences that confound a direct comparison of the results. First, the reference group to which household consumption levels are compared in our study is the median user for all of Cobb County. In contrast, the 
reference group for the OPower studies is significantly smaller - nearby households of similar size. Second, the home energy reports for the OPower studies include emoticons for both the lowest and highest user groups. The extent to which these design differences affect the ways in which households respond to social comparisons remains an open issue.

Finally, our study focuses on the use of normative messages to promote changes in the way households use water. To the extent that such changes reflect behavioral adjustments that require vigilance to maintain over time, it is not surprising that the impacts of such programs wane over time as a ho usehold's attention shifts elsewhere. Y et, one can envision a similar program whereby normative appeals are used to encourage the adoption of new technologies such as low flow shower heads or high efficiency toilets. Such technologies affect consumption through efficiency gains rather than adjustments in patterns of use and thus we would anticipate such a program to have a more persistent effect on demand. However, given the large up-front costs of purchasing such technologies, it is likely that any such program would affect fewer households than a program targeting behavioral adjustments. Which strategy would have a greater impact on aggregate use remains an open question. Studies that compare the relative impact of targeting technology adoption rather than end use would be a fruitful avenue for future work. We suspect that research into these areas will likely lead to insights hitherto uncovered and an improved understanding about the effectiveness of non-pecuniary strategies as a policy instrument. 


\section{References}

Allcott, Hunt, "Social Norms and Energy Conservation," 2009 working paper, Department of Economics, New York University.

Ayres, Ian, Sophie Raseman, and Alice Shih, "Evidence from Two Large Field Experiments that Peer Comparison Feedback Can Reduce Residential Energy Usage,” (2009) NBER working paper 15386.

Bryan, James H. and Mary A. Test, "Models of Helping: Naturalistic Studies in Aiding Behavior," Journal of Personality and Social Psychology, 6 (1967), pp. 400 - 407.

Cialdini, Robert B., Linda J. Demaine, Brad J. Sagarin, Daniel W. Barrett, Kelton Rhoads, and Patricia L. Winter, "Managing Social Norms for Persuasive Impact,” Social Influence, 1 (2006), pp. $3-15$.

Costa, Dora L. and Matthew E. Kahn, “Energy Conservation 'Nudges' and Environmentalist Ideology: Evidence from a Randomized Residential Electricity Field Experiment,” (2010) NBER Working Paper No. 15939.

Croson, Rachel and Jen Shang, “The Impact of Downward Social Information on Contribution Decisions," Experimental Economics, 11 (2008), pp. 221 - 233.

Curtis, Kynda and Michael K. Price, "Reputation or Reciprocity: Gift Exchange in a Labor Market Field Experiment,” working paper, University of Tennessee, Knoxville, 2009.

Frey, Bruno and Stephen Meier, "Social Comparisons and Pro-Social Behavior: Testing ‘Conditional Cooperation' in a Field Experiment,' American Economic Review, 94 (2004), pp. $1717-1722$.

Gneezy, Uri and John A. List, "Putting Behavioral Economics to Work: Testing for Gift Exchange in Labor Markets Using Field Experiments," Econometrica, 74 (2006), pp. $1365-1384$. 
Goldstein, Noah J., Robert B. Cialdini, and Vladas Griskevicius, "A Room with a Viewpoint: Using Social Norms to Motivate Environmental Conservation in Hotels," Journal of Consumer Research, 35 (2008), pp. $472-482$.

Harrison, Glenn W. and John A. List, "Field Experiments," Journal of Economic Literature, 42 (2004), pp. $1009-1055$.

Hutton, R. B., G. A. Mauser, P., Filiatrault, and O.T. Ahtola, "Effects of Cost-Related Feedback on Consumer Knowledge and Consumption Behavior: A Field Experiment Approach,” Journal of Consumer Research, 13 (1986), pp. 327 - 336.

Kurz, Tim, Ngaire Donaghue, and Ian Walker, "Utilizing a Social-Ecological Framework to Promote Water and Energy Conservation: A Field Experiment," Journal of Applied Social Psychology, 35 (2005), pp. 1281 - 1300.

Landry, Craig E., Andreas Lange, John A. List, Michael K. Price, and Nicholas G. Rupp, "Is a Donor in Hand Better than Two in the Bush: Evidence from a Natural Field Experiment," forthcoming American Economic Review.

Levitt, Steven and John A. List, "What do Laboratory Experiments Measuring Social Preferences Reveal about the Real World?" Journal of Economic Perspectives, 21 (2007), pp. $153-174$.

Luyben, P. D., "Prompting Thermostat Setting Behavior: Public Response to a Presidential Appeal for Conservation," Environment and Behavior, 14 (1982), pp. 113 - 128.

Mansur, Erin T. and Sheila M. Olmstead, "The Value of Scarce Water: Measuring the Inefficiency of Municipal Regulations,” NBER Working Paper No. 13513, 2007.

Martin, Richard and John Randal, "How is Donation Behavior Affected by the Donations of Others?", Journal of Economic Behavior and Organization, 67 (2008), pp. 228 - 238. 
Nolan, Jessica M., P. Wesley Schultz, Robert B. Cialdini, Noah J. Goldstein, and Vlada Griskevicius, "Normative Social Influence in Underdetected," Personality and Social Psychology Bulletin, 34 (2008), pp. 913 - 924.

Olmstead, Sheila, W. Michael Hanemann and Robert N. Stavins, "Water Demand under Alternative Price Structures," Journal of Environmental Economics and Management, 54 (2007), pp. $181-198$.

Reingen, Peter H., “On Inducing Compliance with Requests,” The Journal of Consumer Research, 5 (1978), pp. $96-102$.

Sandler, Todd A. and Daniel G. Arce, "Pure Public Goods versus Commons: Benefit-Cost Duality," Land Economics, 79 (2003), pp. 355 - 368.

Schultz, P. Wesley, Jessica M. Nolan, Robert B. Cialdini, Noah J. Goldstein, and Vladas Griskevicius, “The Constructive, Destructive, and Reconstructive Power of Social Norms," Psychological Science, 18 (2007), pp. 429 - 434.

Shang, Jen and Rachel Croson, "Field Experiments in Charitable Contribution: The Impact of Social Influence on the Voluntary Provision of Public Goods," The Economic Journal, 119 (2009), pp. $1422-1439$.

Siero, F.W., A.B. Bakker, G.B. Dekker, and M.T.C. Van den Burg, “ Changing Organizational Energy Consumption Behavior through Competitive Feedback," Journal of Environmental Psychology, 16 (1996), pp. 2235 - 246. 
Table 1: Summary Statistics - Use in Thousands of Gallons

\begin{tabular}{|l|c|c|c|c|}
\hline & $\begin{array}{c}\text { Summer '07 } \\
\text { Use }\end{array}$ & $\begin{array}{c}\text { \% Change } \\
\text { Relative to } \\
\text { Summer '06 }\end{array}$ & $\begin{array}{c}\text { Water '06 } \\
\text { Use }\end{array}$ & $\begin{array}{c}\text { April-May '07 } \\
\text { Use }\end{array}$ \\
\hline Control Group & 36.47 & $-7.83 \%$ & 58.29 & 15.89 \\
$(\mathrm{~N}=71643)$ & $(29.25)$ & & $(41.38)$ & $(12.02)$ \\
\hline Treatment 1 - Technical Advice & 36.35 & $-8.41 \%$ & 58.43 & 15.98 \\
$(\mathrm{~N}=11675)$ & $(30.42)$ & & $(39.96)$ & $(11.74)$ \\
\hline Treatment 2 - Weak Social Norm & 35.43 & $-10.08 \%$ & 58.18 & 15.88 \\
$(\mathrm{~N}=11675)$ & $(28.13)$ & & $(41.25)$ & $(11.69)$ \\
\hline Treatment 3 - Strong Social Norm & 34.86 & $-12.01 \%$ & 58.43 & 15.98 \\
$(\mathrm{~N}=11676)$ & $(26.34)$ & & $(40.67)$ & $(11.53)$ \\
\hline
\end{tabular}

Note: Cell entries are average use levels in thousands of gallons and associated standard deviations (in parentheses).

Table 2: Average Treatment Effects - Linear Regression Models

\begin{tabular}{|c|c|c|c|}
\hline & Model A & Model B & Model C \\
\hline Constant & $\begin{array}{l}2.18^{* *} \\
(0.43)\end{array}$ & $\begin{array}{c}1.87 \\
(1.59)\end{array}$ & $\begin{array}{c}4.59 * * \\
(0.26)\end{array}$ \\
\hline $\begin{array}{l}\text { Indicator for Treatment } 1 \text { - Technical } \\
\text { Advice }\end{array}$ & $\begin{array}{l}-0.24 \\
(0.19)\end{array}$ & $\begin{array}{l}-0.24 \\
(0.19)\end{array}$ & $\begin{array}{l}-0.37^{*} \\
(0.16)\end{array}$ \\
\hline $\begin{array}{l}\text { Indicator for Treatment } 2-\text { Weak } \\
\text { Social Norm }\end{array}$ & $\begin{array}{c}-0.99 * * \\
(0.17)\end{array}$ & $\begin{array}{c}-0.99 * * \\
(0.17)\end{array}$ & $\begin{array}{c}-1.01 * * \\
(0.16)\end{array}$ \\
\hline $\begin{array}{l}\text { Indicator for Treatment } 3 \text { - Strong } \\
\text { Social Norm }\end{array}$ & $\begin{array}{c}-1.74^{* *} \\
(0.17)\end{array}$ & $\begin{array}{c}-1.74^{* *} \\
(0.17)\end{array}$ & $\begin{array}{c}-1.66^{* *} \\
(0.16)\end{array}$ \\
\hline Water Use from May-Oct 2006 & $\begin{array}{l}0.37 * * \\
(0.01)\end{array}$ & $\begin{array}{l}0.35^{* *} \\
(0.01)\end{array}$ & $\begin{array}{l}0.34 * * \\
(0.01)\end{array}$ \\
\hline Water Use in April and May 2007 & $\begin{array}{l}0.79^{* *} \\
(0.04)\end{array}$ & $\begin{array}{l}0.83 * * \\
(0.04)\end{array}$ & $\begin{array}{l}0.74 * * \\
(0.04)\end{array}$ \\
\hline Route Fixed Effects & No & Yes & No \\
\hline Trimming Rule & None & None & Yes \\
\hline \# of Observations & 10669 & 10669 & 105885 \\
\hline R-Squared & 0.62 & 0.63 & 0.60 \\
\hline
\end{tabular}

Note: Cell entries are parameter estimates (standard errors in parentheses) for a series of linear regression models of aggregate water use (in thousands of gallons) for summer 2007 on the included covariates. The models differ in whether route specific fixed effects are included and the rules used to trim the overall sample. The third column excludes observations from the top and bottom 0.25 percentile of the distribution for summer 2007 water use. Cell entries can be read as follows - as indicated in column 1, households that were randomly assigned into the strong social norm treatment consumed approximately 1,740 fewer gallons on average than those in the control group. 
Table 3: Heterogeneity in Treatment Effects - Low versus High User Groups

\begin{tabular}{|l|c|c|}
\hline & Model A & Model B \\
\hline Constant & $6.68^{* *}$ & $2.21^{* *}$ \\
& $(2.31)$ & $-0.69)$ \\
\hline Indicator for Treatment 1 - Technical Advice & -0.21 & -0.25 \\
& $(0.18)$ & $-1.28)$ \\
\hline Indicator for Treatment 2 - Weak Social Norm & $-0.46^{* *}$ & $(0.26)$ \\
\hline Indicator for Treatment 3 - Strong Social Norm & $(0.16)$ & $-2.35^{* *}$ \\
& $-0.57^{* *}$ & $(0.24)$ \\
\hline Water Use from May-Oct 2006 & $(0.16)$ & $0.37^{* *}$ \\
& $0.22^{* *}$ & $(0.01)$ \\
\hline Water Use in April and May 2007 & $(0.08)$ & $0.79^{* *}$ \\
& $0.77^{* *}$ & $(0.04)$ \\
\hline \multicolumn{2}{|c|}{} \\
\hline Sample Restriction & $(0.15)$ & Top 50\% \\
\hline \multicolumn{2}{|c|}{ Bottom 50\% } & 69309 \\
\hline \# of Observations & 37360 & 0.58 \\
\hline R-Squared & 0.17 & $*$ Denotes statistical significance at $\mathrm{p}<0.01$ level \\
\multicolumn{2}{|c|}{} & $*$ Denotes statistical significance at $\mathrm{p}<0.05$ level
\end{tabular}

Note: Cell entries are parameter estimates (standard errors in parentheses) for a series of linear regression models of aggregate water use (in thousands of gallons) for summer 2007 on the included covariates. The models in the first (second) column include only those households who consumed less water (more water) during the summer of 2006 than the median household in Cobb County. 
Table 4: The Persistence of Treatment Effects - Comparing July and October Use

\begin{tabular}{|c|c|c|c|c|c|c|}
\hline & $\begin{array}{l}\text { Model A } \\
\text { June Use }\end{array}$ & $\begin{array}{l}\text { Model B } \\
\text { Sept Use }\end{array}$ & $\begin{array}{l}\text { Model C } \\
\text { June Use }\end{array}$ & $\begin{array}{l}\text { Model D } \\
\text { Sept Use }\end{array}$ & $\begin{array}{l}\text { Model E } \\
\text { June Use }\end{array}$ & $\begin{array}{l}\text { Model F } \\
\text { Sept Use }\end{array}$ \\
\hline Constant & $\begin{array}{c}4.07 * * * \\
(0.17)\end{array}$ & $\begin{array}{c}4.54 * * * \\
(0.22)\end{array}$ & $\begin{array}{c}4.88 * * * \\
(0.06)\end{array}$ & $\begin{array}{c}3.87 * * * \\
(0.06)\end{array}$ & $\begin{array}{c}5.28 * * * \\
(0.28)\end{array}$ & $\begin{array}{c}5.76 * * * \\
(0.32)\end{array}$ \\
\hline $\begin{array}{l}\text { Indicator for } \\
\text { Technical Advice } \\
\text { Treatment }\end{array}$ & $\begin{array}{l}-0.09 \\
(0.08)\end{array}$ & $\begin{array}{l}-0.02 \\
(0.07)\end{array}$ & $\begin{array}{c}-0.12 * * \\
(0.06)\end{array}$ & $\begin{array}{l}-0.05 \\
(0.06)\end{array}$ & $\begin{array}{l}-0.09 \\
(0.11)\end{array}$ & $\begin{array}{l}-0.02 \\
(0.10)\end{array}$ \\
\hline $\begin{array}{l}\text { Indicator for Weak } \\
\text { Social Norm } \\
\text { Treatment }\end{array}$ & $\begin{array}{c}-0.32 * * * \\
(0.07)\end{array}$ & $\begin{array}{c}-0.18 * * * \\
(0.06)\end{array}$ & $\begin{array}{c}-0.16 * * * \\
(0.06)\end{array}$ & $\begin{array}{l}-0.12 * \\
(0.07)\end{array}$ & $\begin{array}{c}-0.38 * * * \\
(0.11)\end{array}$ & $\begin{array}{c}-0.19 * * \\
(0.09)\end{array}$ \\
\hline $\begin{array}{l}\text { Indicator for Strong } \\
\text { Social Norm } \\
\text { Treatment }\end{array}$ & $\begin{array}{c}-0.51 * * * \\
(0.07)\end{array}$ & $\begin{array}{c}-0.29 * * * \\
(0.07)\end{array}$ & $\begin{array}{l}-0.09 \\
(0.07)\end{array}$ & $\begin{array}{l}-0.10^{*} \\
(0.06)\end{array}$ & $\begin{array}{c}-0.74 * * * \\
(0.10)\end{array}$ & $\begin{array}{c}-0.40 * * * \\
(0.10)\end{array}$ \\
\hline $\begin{array}{l}\text { Water Use in June } \\
2006\end{array}$ & $\begin{array}{c}0.50 * * * \\
(0.02)\end{array}$ & & $\begin{array}{c}0.09 * * * \\
(0.01)\end{array}$ & & $\begin{array}{c}0.46 * * * \\
(0.02)\end{array}$ & \\
\hline $\begin{array}{l}\text { Water Use in Sept } \\
2006\end{array}$ & & $\begin{array}{c}0.44 * * * \\
(0.03)\end{array}$ & & $\begin{array}{c}0.30 * * * \\
(0.01)\end{array}$ & & $\begin{array}{c}0.39 * * * \\
(0.03)\end{array}$ \\
\hline User Type & All & All & $\begin{array}{l}\text { Below } \\
\text { Median }\end{array}$ & $\begin{array}{l}\text { Below } \\
\text { Median }\end{array}$ & $\begin{array}{l}\text { Above } \\
\text { Median }\end{array}$ & $\begin{array}{l}\text { Above } \\
\text { Median }\end{array}$ \\
\hline \# of Observations & 106669 & 106669 & 37360 & 37360 & 69309 & 69309 \\
\hline R-Squared & 0.36 & 0.18 & 0.01 & 0.02 & 0.31 & 0.14 \\
\hline
\end{tabular}

Note: Cell entries are parameter estimates (standard errors in parentheses) from linear regressions of June/September 2007 water consumption on the included model covariates. 
Figure 1: Estimated Treatment Effects - All and Trimmed Data

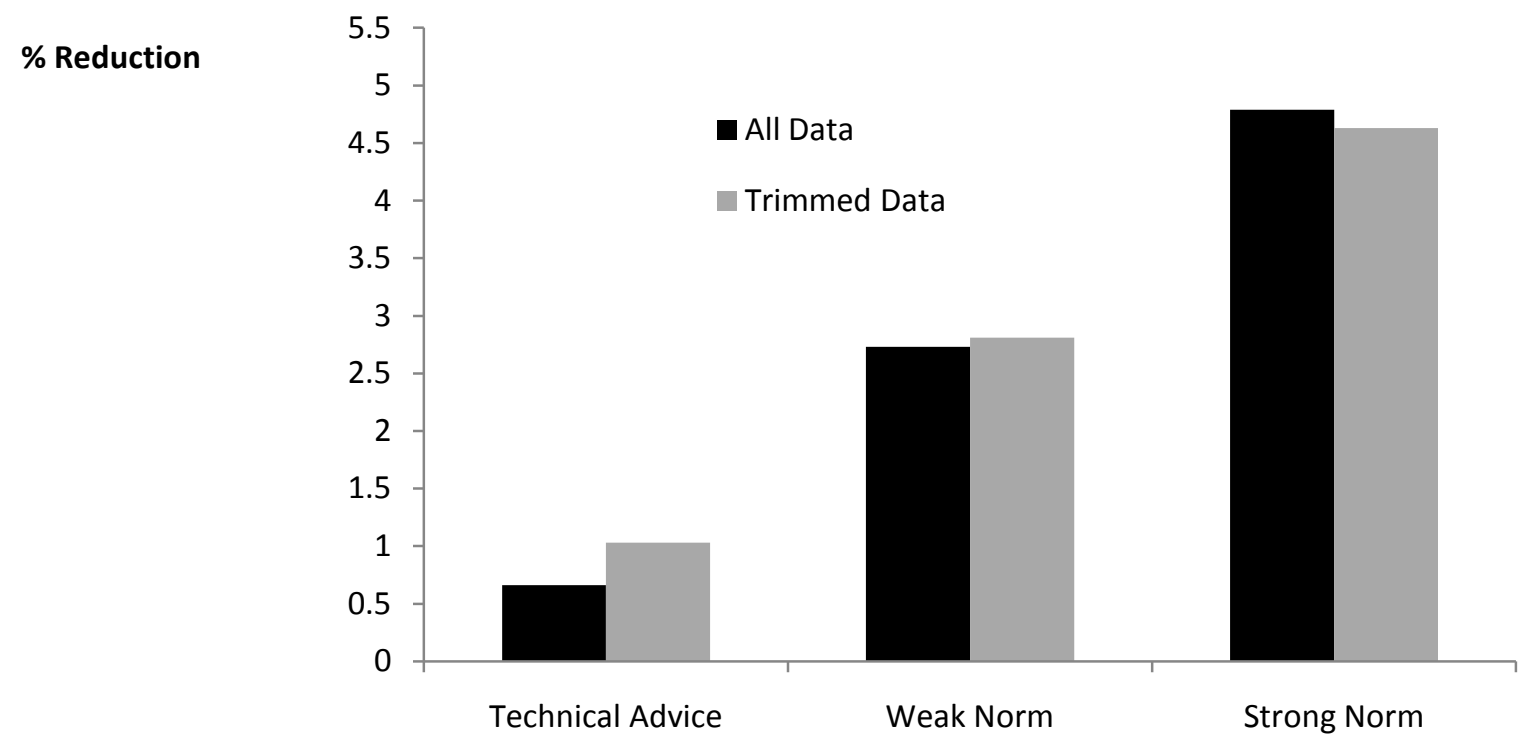

Figure 2: Estimated Treatment Effects by User Group

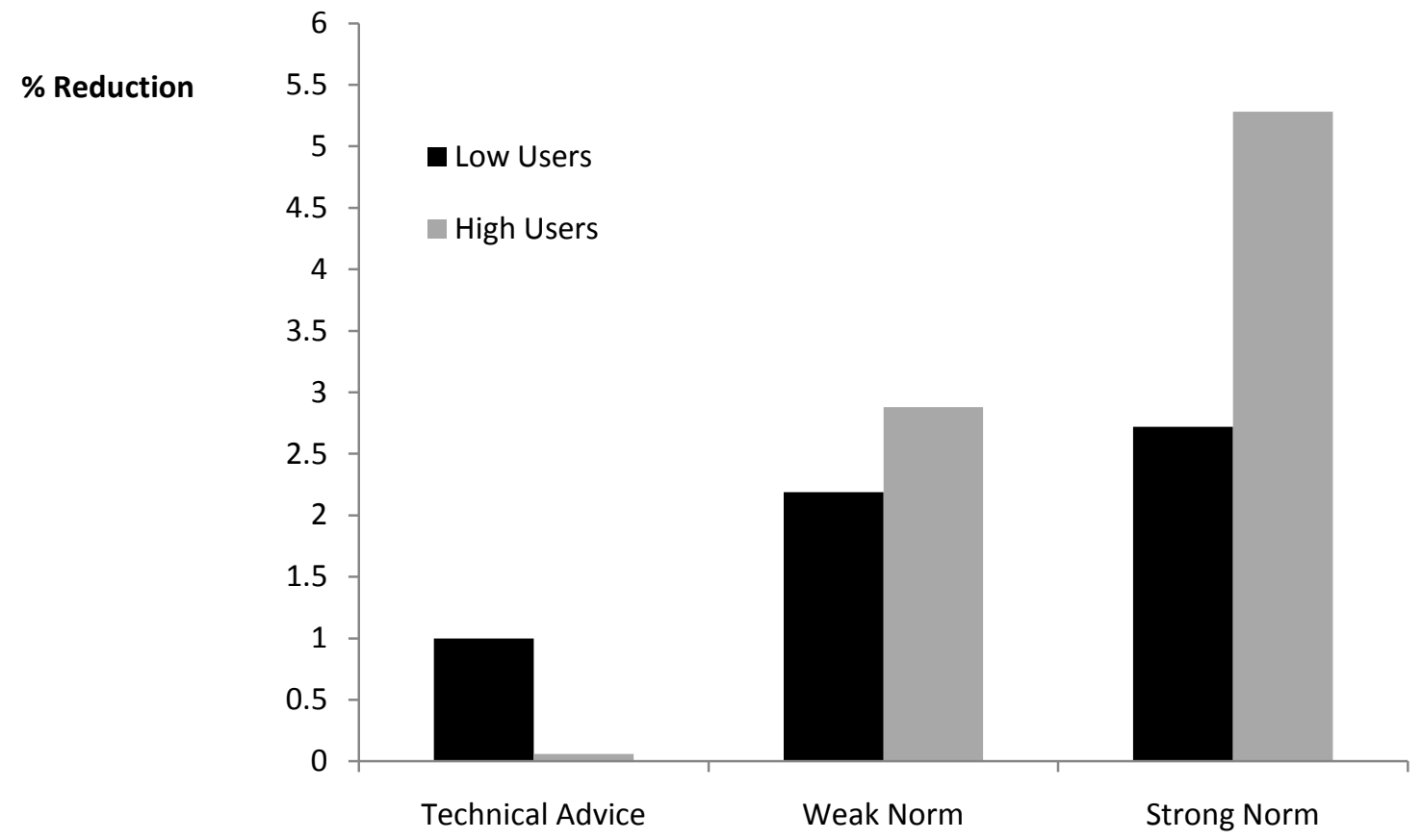


Figure 3: Estimated Treatment Effects by Month

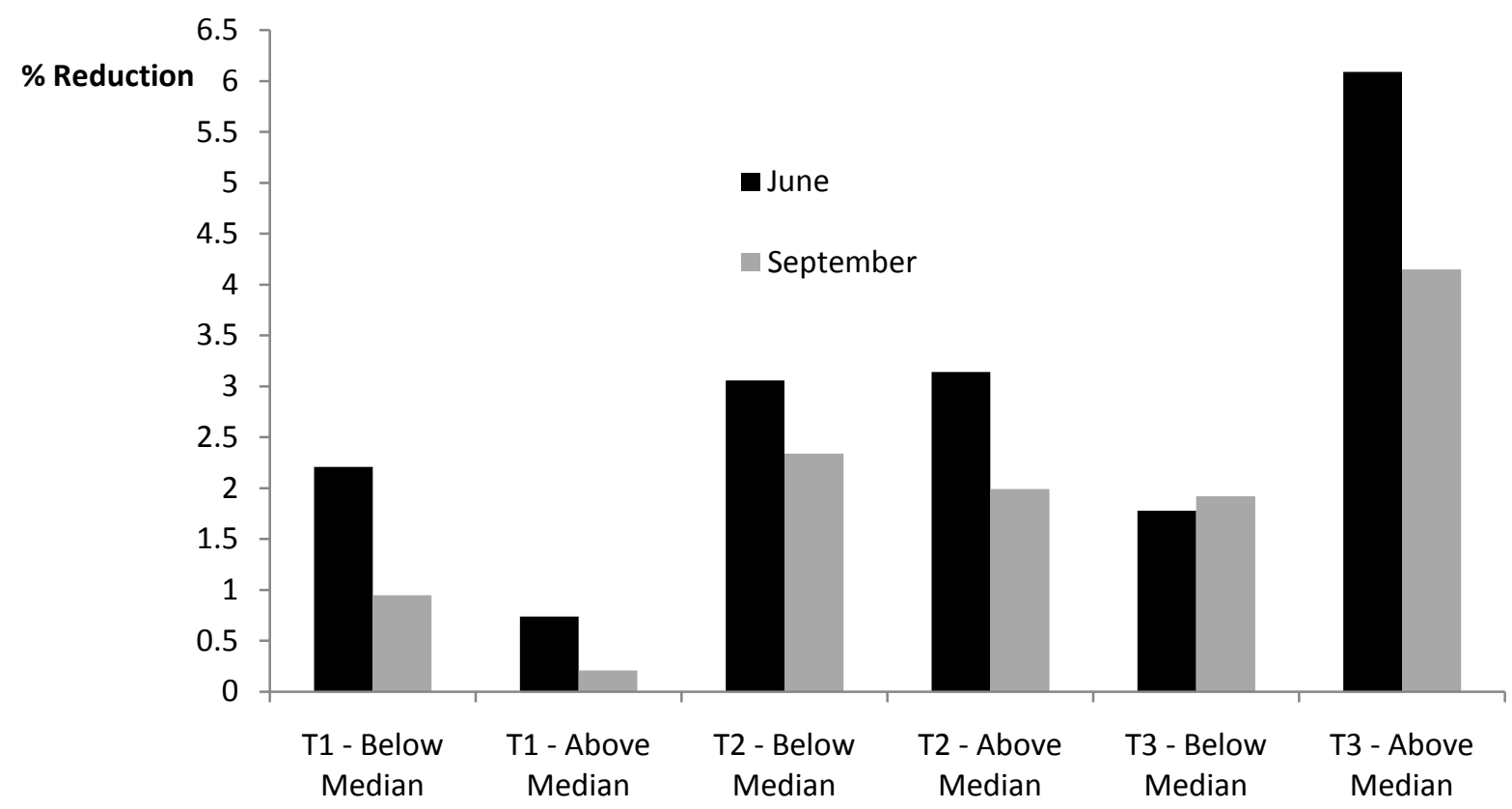




\section{Appendix 1: Tip Sheet and Sample Treatment Letters}

\section{Simple Ways to Reduce Water Consumption}

\section{Outdoor Water Use}

- Fix leaking sprinklers, spigots and hoses. One broken sprinkler can use an additional 100 gallons in a typical 10 minute watering cycle.

- Raise your lawn mower blade to at least 3 inches. This encourages grass roots to grow deeper, shades the roots and holds soil moisture better than a closely clipped lawn

- Water your lawn with only one inch of water every seven to ten days (less often if we've had rain). Overwatered lawns and plants grow shallow roots and are more likely to die in periods of drought.

- Don't water between 10 am and midnight. The water evaporates before plants can use it.

- Use a low-flow nozzle on your hose. Using a standard nozzle on your hose to wash your car or plants can require hundreds of gallons more water than a low-flow nozzle.

- Mulch! Using pine straw, bark chips or ground hardwood mulch on the roots of plants and trees helps the soil retain water.

- Use plants appropriate for our climate. Ask your local nursery about drought-tolerant plants and trees appropriate for Georgia. See next page for more information.

- Do not use a hose to clean your driveway or sidewalk. Use a broom instead and save hundreds of gallons of water.

\section{Toilets, Faucets, Showers and Washing Machines}

\section{Did You Know?}

A showerhead or faucet leak of one drop per second adds up to 2,700 gallons/year!
- Fix toilet leaks: This can save you thousands of gallons of water each year!

- Turn off the bathroom faucets when brushing and shaving: Save up to 3,000 gallons/year!

- Don't use your toilet as a wastebasket.

- Replace your old toilet. If you have a pre-1993 toilet, you can save more than 16,000 gallons per year by purchasing a high-efficiency model (1.3 - 1.6 gallons per flush). Unlike the first generation of low-flow toilets, new models reduce water use without sacrificing performance.

- Replace your old faucets and showerheads. High-efficiency sink faucets (1.5 gallons per minute or less) and accessories (like aerators) can reduce this standard flow by more than 30 percent without sacrificing performance.

- Take short showers rather than baths: Taking a five-minute shower uses 10 to 25 gallons as opposed to $30-70$ gallons for a bath. If you take a bath, stopper the drain immediately and adjust the temperature as you fill the tub.

- Run full laundry loads or use the appropriate load size selection on the machine.

- When you replace your old washing machine, purchase a high-efficiency washing machine that uses less than 27 gallons of water per load.

Everywhere You Look, You'll Find Another Easy Way to Reduce Water Consumption 


\section{Detecting Hidden Leaks}

To detect hidden leaks:

- Read your water meter before and after a two-hour period when no water is being used. If the meter does not read exactly the same, you probably have a leak. To download a guide to reading your meter, please visit water.cobbcountyga.gov/files/meterhowto.pdf *

To tell if your toilet has a leak:

- Place a drop of food coloring in the tank; if the color shows in the bowl without flushing, you have a leak in the tank.

- To see if the leak is coming from the flush valve, shut off the water supply to the toilet. Mark the water level on the inside of the tank with a pencil. Check the water level in 10 or 20 minutes. If the water has fallen, you know the flush valve is leaking.

- If the water seems to run constantly in the toilet, your refill valve may be leaking. In this case, the tank overfills and the excess water runs into the overflow pipe and into the bowl.

For more information and repair tips, Ace Hardware has an excellent FAQ section, as well as installation guides, in the Projects \& Solutions section of their website: www.acehardware.com/infohome/. Home Depot also has guides in the Know-How section of their website at homedepot.com

\section{Advice on Proper Yard Watering}

Cobb County provides instructions on proper yard watering

- Call 770-419-6244, or

- Download the guide at water.cobbcountyga.gov/files/InigationAudit.pdf

ConserveWater Georgia offers plenty of information, tips, and creative ideas.

- Download their WaterWise Landscaping \&Watering Guide at www.conservewatergeorgia.net/pdf/waterwiseguide.pdf.

Find the right plants and trees for your yard!

- Online guides to appropriate plants and trees for Georgia can be found at: -georgiagaces.caes.uga.edu Search for "drought-resistant" (georgiafaces.caes.uga.edu/getstory. cfm?storyid=1165)

-www marshalltrees.com Go to "Educational Information," then "Trees During Design \& Develop ment." The "Tree Selection" section has a link for "Drought Resistance" (www.marshalltrees.com/ articles. asp? $\mathrm{p}=2$ \&id $=26 \&$ cid $=0$ )

How you design your landscape is also important. Check out the following guides:

- http://www.conservewatergeorgia.net/pdf/medc_water_saving_tips_new_landscape.pdf

- http://pubs.caes.uga.edu/caespubs/pubcd/B1073 htm.

\section{Audit Your Usage}

To help you leam more about how much water you are using in your home, Cobb County has a quick, 2-page home water audit that you can complete: http://water.cobbcountyga.gov/files/wateraudit.pdf. By completing this questionnaire and submitting it to the Water Efficiency Program, you may qualify for FREE water saving devices and water efficiency information

*Any documents on-line that have a "pdf' extension require Adobe Reader. You can download it for free at: http:/www.adobe. com/products/acrobat/readstep $2 \mathrm{hml}$ 


\section{Sample Letter - Weak Social Norm Treatment}

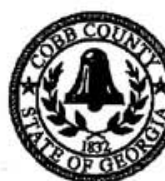

Treatment 2

Cobb County...Expect the Best!

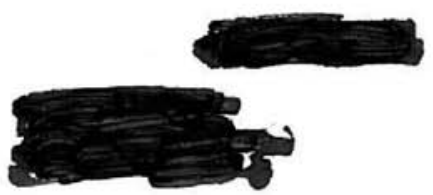

May 2007

Dear Members of the Residence,

As you may know, Cobb County's water resources are stretched because of population growth and many years of low rainfall. Cobb County residents consume almost one out of every ten gallons of Georgia's public water supply. As a result, our water use has a large impact on the ability of Georgia's waterways to protect wildlife and dilute pollutants that threaten human health. We all need to work together to use water wisely.

As we enter the summer months, we thought that you might be interested in the following information about your water consumption last year:

Your own total consumption June to October 2006:

142,000 gallons

Cobb County now charges higher prices as you consume more water. So reducing your water consumption can save you money. It can also protect your landscaping investments: people tend to overwater their lawn and plants. Overwatered plants grow shallow roots and are more likely to die in periods of drought.

We have enclosed a tip sheet that lists proven ways to reduce your water consumption. You can obtain more information on-line (http://water.cobbcountyga. gov/efficiency.htm and http://www.wateruseitwisely.com/) or by contacting Ms. Kathy Nguyen, Water Conservation Coordinator, at 770-419-6244 or Kathy.Nguyen@cobbcounty.org.

We need your help. Act on the tips listed in the enclosed tip sheet. We all have to do our part to protect Cobb County's precious water resources. Reducing our water consumption today is important for preserving our environment and our economy for future generations. Please don't waste water. Remember: every drop counts!

Thank you for your attention.

Sincerely,

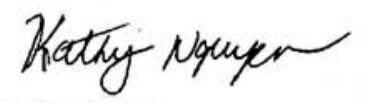

Kathy Nguyen

Water Conservation Coordinator

Mayr2007 Treatment Lt: F1 


\section{Sample Letter - Strong Social Norm Treatment}
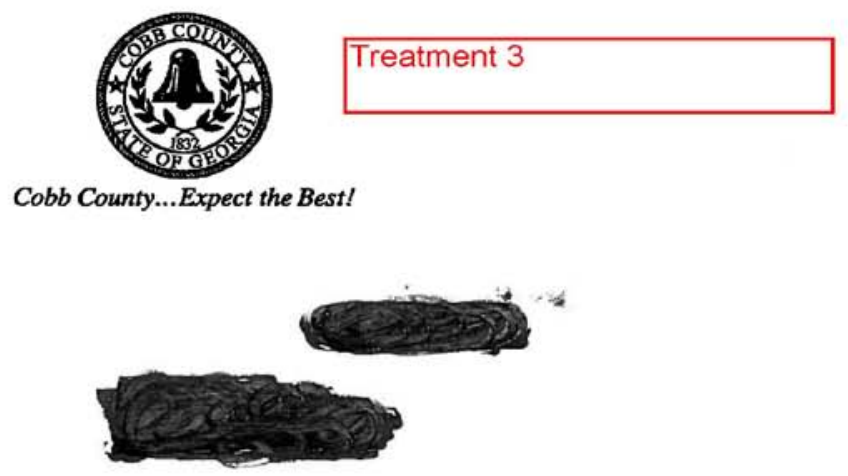

May 2007

Dear Members of the Residence,

As you may know, Cobb County's water resources are stretched because of population growth and many years of low rainfall. Cobb County residents consume almost one out of every ten gallons of Georgia's public water supply. As a result, our water use has a large impact on the ability of Georgia's waterways to protect wildlife and dilute pollutants that threaten human health. We all need to work together to use water wisely.

As we enter the summer months, we thought that you might be interested in the following information about your water consumption last year:

Your own total consumption June to October 2006:

50,000 gallons

Your neighbors' average (median) consumption June to October 2006:

35,000 gallons

You consumed more water than $72 \%$ of your Cobb County neighbors.

We have enclosed a tip sheet that lists proven ways to reduce your water consumption. You can obtain more information on-line (http://water.cobbcountyga.gov/efficiency.htm and http://www.wateruseitwisely.com/) or by contacting Ms. Kathy Nguyen, Water Conservation Coordinator, at 770-419-6244 or Kathy.Nguyen@.cobbcounty.org.

We need your help. Act on the tips listed in the enclosed tip sheet. We all have to do our part to protect Cobb County's precious water resources. Reducing our water consumption today is important for preserving our environment and our economy for future generations. Please don't waste water. Remember: every drop counts!

Thank you for your attention.

Sincerely,

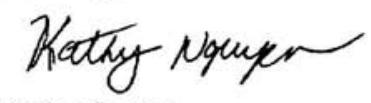

Kathy Nguyen

Water Conservation Coordinator 